DOI: http://dx.doi.org/10.18764/2358-4319.v10n3p13-40

\title{
Os professores de engenharia no Brasil e em Portugal ${ }^{1}$
}

\author{
Sandra Terezinha Urbanetz ${ }^{2}$ \\ Maria Amélia da Costa Lopes ${ }^{3}$
}

\section{RESUMO}

Há muito que se discute o modelo mais adequado para um sistema de ensino que contemple as demandas sociais ocorridas em razão das mudanças no mundo do trabalho, no qual a exigência de conhecimento científico, tecnológico e sócio-histórico se faz presente de forma cada vez mais intensa. Este artigo apresenta uma pesquisa desenvolvida com o objetivo de evidenciar a trajetória de constituição docente dos engenheiros, ou seja, identificar como os engenheiros tornam-se professores, bem como discutir o papel da formação pedagógica na constituição desses docentes. Para tanto foram realizadas entrevistas com professores de um curso de mestrado integrado em Engenharia EletrotécnicaedeComputadoresemPortugaledeumcursodeEngenharia Eletrônica no Brasil, com vista a dar conta do itinerário formativo e das características de percurso desses profissionais. Foram considerados os aspectos de motivação para ingresso na carreira docente, as mudanças, dificuldades e possibilidades encontradas nesse percurso, a formação pedagógica necessária e o sentimento de realização profissional. Os resultados indicam que os professores se sentem plenamente realizados profissionalmente, abertos a uma constante melhoria pedagógica, e que a formação pedagógica necessária ao desenvolvimento das atividades educativas estão vinculadas a demandas institucionais e pessoais dos professores.

Palavras-chave: Formação de professores; itinerário formativo; engenharia.

1 Pesquisa realizada em Portugal com apoio da CAPES.

2 Pós Doutora pela Universidade do Estado do Rio de Janeiro e pela Faculdade de Psicologia e Ciências da Educação da Universidade do Porto - Portugal. Professora do Instituto Federal do Paraná - IFPR, Campus Curitiba, professora da Pós Graduação em Educação Profissional Técnica em Nível Médio. E-mail: sandra.urbanetz@ifpr.edu.br

3 Professora Doutora da Faculdade de Psicologia e Ciências da Educação da Universidade do Porto.E-mail: amelia@fpce.up.pt 


\title{
Engineering teachers in Brazil and Portugal
}

\begin{abstract}
There has been a discussion for a long time about the most adequate model for a teaching system that looks on the social demands that have occurred due to changes in the working world, in which the demand for scientific, technological and socio-historical knowledge is increasingly present in an intensive manner. This article presents a research developed with the objective of showing the trajectory of engineering teachers' training, that is, to identify how engineers become teachers, as well as to discuss the role of the pedagogical training in the formation of these teachers. For this purpose, interviews were conducted with teachers from a master's degree integrated with Electronic and Computing Engineering in Portugal and an Electronic Engineering course in Brazil, in order to account for the training itinerary and the trajectory characteristics of these professionals. The motivation aspects to enter the teaching career, the changes, difficulties and possibilities found in this course, the necessary pedagogical training and the feeling of professional fulfillment were considered. The results indicate that teachers feel completely fulfilled professionally, open to a constant pedagogical improvement, and that the pedagogical training necessary for the development of educational activities are linked to the institutional and personal demands of teachers.
\end{abstract}

Keywords: Teachers' training; training itinerary; engineering

\section{Los profesores de ingenería enBrasil y en Portugal}

\section{RESUMEN}

Hace mucho que se discute el modelo más adecuado para un sistema de enseñanza que contemple las demandas sociales ocurridas en razón de los cambios en el mundo del trabajo, en el cual la exigencia de conocimiento científico, tecnológico y socio-histórico se hace presente de forma cada vez más intensa. Este artículo presenta una investigación desarrollada con el objetivo de evidenciar la trayectoria de constitución docente de los ingenieros, o sea, identificar como los ingenieros se vuelven profesores, así como discutir el papel de la formación pedagógica en la constitución de esos docentes. Para ese fin fueron realizadas entrevistas con profesores de un curso de maestría 
integrado en Ingeniería Electrotécnica y de Ordenadores en Portugal y de un curso de Ingeniería Electrónica en Brasil, con vista a tomar en cuenta el itinerario formativo y las características del recorrido de esos profesionales. Fueron considerados los aspectos de motivación para ingreso en la carrera docente, los cambios, dificultades y posibilidades encontradas en ese recorrido, la formación pedagógica necesaria y el sentimiento de realización profesional. Los resultados indican que los profesores se sienten plenamente realizados profesionalmente, abiertos a una constante mejoría pedagógica, y que la formación pedagógica necesaria al desarrollo de las actividades educativas están vinculadas a demandas institucionales y personales de los profesores.

Palabras clave: Formación de profesores; itinerario formativo; ingeniería

\section{Introdução}

Esse artigo tem como objetivo discutir a trajetória profissional dos professores do ensino superior de duas Universidades, uma brasileira e uma portuguesa, particularmente da área de engenharia bem como contribuir para o debate a cerca da formação pedagógica para esses docentes.

Discutir a formação dos professores permanece como uma temática instigante pois significa compreender a complexidade do sistema de ensino em suas diversas manifestações. Isso posto, apresenta-se o que levou à definição do problema que orienta a investigação proposta: Como o profissional da área da engenharia constitui-se como docente?

A necessidade de delimitar o campo de investigação, em razão da amplitude de possibilidades, levou à escolha da engenharia como formação inicial devido a sua relevância na constituição do capitalismo industrial, o qual deu origem às iniciativas públicas e privadas de formação profissional.

Estudos apontam que os engenheiros professores atuam a partir de um conhecimento pedagógico tácito, uma vez que esta foi desenvolvida por meio de um trabalho pedagógico real o que nos leva a questionar o clamor sobre a formação pedagógica dos professores do ensino superior.

Assim sendo, o artigo organiza-se no início com o enquadramento teórico, desenvolvido a partir dos elementos teóricos do trabalho enquanto categoria de formação humana seguido da discussão sobre 
a formação dos professores de engenharia a partir de autores que discutem essa temática. Em seguida, apresenta-se como o estudo foi desenvolvido metodologicamente apresentando os dois contextos e os participantes.

Na sequência faz-se a descrição e a discussão dos resultados da análise efetivada a partir dos aspectos selecionados: motivação para ingresso na carreia docente, mudanças, dificuldades e possibilidades encontradas nessa trajetória, formação pedagógica e realização profissional.

\section{Enquadramento teórico}

\section{Trabalho e formação num mundo em mudança}

Uma das demandas sociais mais presente nas discussões sobre a formação de professores diz respeito à qualificação continuada, de caráter teórico-prático, substituindo a proposta de formar o indivíduo certo para o lugar certo como paradigma do modo de produção taylorista-fordista.

A formação continuada tal como é concebida no Brasil hoje, apresenta-se como consequência da concepção de flexibilização das possibilidades de atuação no mundo do trabalho, a partir do regime de acumulação flexível, que destrói a relação direta entre qualificação e exercício profissional. Neste regime de acumulação, o ingresso no mundo do trabalho ocorre, não a partir da oferta de qualificação, mas a partir da demanda do processo produtivo. Assim, um mesmo trabalhador pode desempenhar numerosas e diversificadas atividades ao longo de sua vida de trabalho, independentemente de sua qualificação. (KUENZER, 2003). Desta forma, também se flexibiliza a formação, que passa a ter um caráter mais geral na formação inicial, para ir se complementando com educação continuada a partir das necessidades do trabalho a ser realizado. Assim, a partir do momento em que não se tem mais uma única possibilidade de atuação profissional, também não se tem mais um único percurso formativo. Isso obriga, de certa forma, as empresas a investirem na capacitação continuada de seus trabalhadores para que estes atendam às necessidades específicas da organização onde atuam, bem como às mudanças em tecnologia e em gestão que vão ocorrendo ao longo do tempo o que acaba por influenciar as concepções e práticas 
das universidades, uma vez que elas estão inseridas nas mesmas relações sociais e produtivas da sociedade.

Na transição do taylorismo-fordismo para o toyotismo, algumas questões foram aparentemente resolvidas, como a quebra do paradigma de que existe um conhecimento pronto e acabado, que banalizava a concepção de competência, baseada apenas no "como fazer". Contudo, no toyotismo, a partir da intensiva utilização da base microeletrônica, passou-se a reconhecer a necessidade um conhecimento mais geral, exigindo uma formação teórica mais sólida, o que, contraditoriamente, também possibilita a qualificação dos trabalhadores e embora a formação politécnica não se coloque ainda como possibilidade concreta, há que reconhecer a positividade das demandas do capital pela ampliação da formação teórica via atividade educativa sistematizada para os trabaIhadores.

Minimamente, o que se evidencia é o esforço por uma formação polivalente, que supera a formação fragmentada anterior. Com o professor, esse processo não é diferente - ainda que nesse caso seja preciso considerar outros aspectos e dimensões -, pois cabe a ele assumir, gradativamente, múltiplas tarefas nem sempre vinculadas ao processo educativo. Exemplos disso são os processos e programas de educação que abrem vagas para a atuação de professores nos mais diversos espaços, sem exigir, muitas vezes, a qualificação e formação teórica necessárias para tal especificidade.

\section{A formação de professores de engenharia}

A dicotomia entre trabalho intelectual e trabalho manual está presente nos mais diversos momentos históricos da humanidade, mas encontra-se especialmente materializada na forma de produção atual onde o domínio da técnica nem sempre vem acompanhada do domínio da ciência.

Esse fenômeno se reflete nas propostas de formação de professores mediante a distinção entre aqueles que vão pensar os processos pedagógicos de formação acadêmica e aqueles que vão ensinar o trabaIho. Como no taylorismo/fordismo geralmente quem ensinava o trabaIho era um trabalhador que se qualificava pela sua experiência, é compreensível a pouca relevância atribuída à formulação de propostas de formação de professores nas chamadas áreas técnicas, onde se encontra a engenharia. 
As modificações ocorridas no modo de produção, de mecânica para elétrica e, hoje, para a microeletrônica, apontam uma alteração na maneira como o trabalhador é visto e exigido. A partir dessa nova organização do trabalho passou-se a exigir outro comportamento, um novo conhecimento. A divisão rígida entre o trabalho manual e o trabalho intelectual cede espaço para uma organização mais descentralizada, uma vez que as tarefas demandam, nos mais diferentes níveis organizacionais, capacidade de pensar, analisar, decidir, etc. ao mesmo tempo em que se executam tarefas cotidianas.

Fazendo uma breve contextualização da produção acadêmica sobre a formação dos professores com a finalidade de indicar as atuais tendências e especialmente situar no quadro destes estudos a formação do professor para a área de engenharia, verifica-se que poucos estudos tratam da temática, tanto no Brasil quanto em Portugal.

Em Portugal o debate sobre a formação de professores, principalmente a partir do Processo de Bolonha tem se debruçado sobre vários aspectos importantíssimos, porém, tal como no Brasil, a discussão sobre a formação de professores das chamadas áreas técnicas ainda deixa a desejar.

Segundo Manzano (2008), baseado em autores como Tardif (2002), Schön (2000), Perrenoud $(2000,2002)$ entre outros, observa-se que na Revista Brasileira de Educação, de 1995 a 2005 a maior parte da produção sobre a formação de professores diz respeito à discussão sobre a necessidade da reflexão como categoria de formação.

As principais abordagens sobre a formação de professores no Brasil, localizadas em periódicos especializados e no banco de teses e dissertações da Capes, apontaram para os aspectos de discussão sobre a problemática vinculada à resolução de problemas diretamente relacionados à prática e fortemente influenciados pelas discussões de cunho reflexivo.

Autores como, Schon (1991,1992), Nóvoa (1992,2000), Zeichner (1998), Perrenoud $(2000,2002)$ e Tardif (2002) são alguns dos exemplos presentes nas referências dos trabalhos de pesquisadores brasileiros e portugueses.

As pesquisas que se dedicam a histórias de vida (LELIS, 2001) aparecem no cenário dos estudos sobre a formação de professores e publicações a respeito da valorização dos saberes da experiência de professores (SOUSA et al., 1996; KRAMER, 1998). Sobre as novas tecnologias e 
suas implicações para a formação de professores, aparecem os estudos de Menezes (1998), Kenski (1998), Pretto (2002), Silva Jr. (2003), entre outros.

Procedendo à crítica da tendência predominante nos estudos de formação de professores sob a perspectiva do professor reflexivo, aparecem os estudos de Vargas (2003), Silva (2005), Carvalho (2005), Duarte (2001; 2006), Kuenzer (1999; 2008), para citar alguns, que revelam o esvaziamento da formação dos professores com a valorização da prática centrada na ação e no desempenho técnico em detrimento do aprofundamento teórico, com o que se fragiliza a formação crítica que articule teoria e prática a partir da totalidade das relações sociais. Moraes (2003) explicita esse movimento por meio da metáfora do iluminismo às avessas, indicando os retrocessos que significam essa perspectiva.

E, em relação à discussão sobre as competências, é Ramos (2001) quem nos esclarece sobre a complexidade desse conceito.

Nas pesquisas sobre a formação de professores para disciplinas específicas, discute-se a necessidade de uma preparação que abrange não só a formação do conteúdo vinculado à disciplina trabalhada, mas também à formação didática demandada, a exemplo dos trabalhos de Musatti (2003) e Moreira e David (2005).

Existem também trabalhos discutindo o multiculturalismo ou questões culturais de maneira ampla dentro da perspectiva de formação de professores; são eles os estudos de Monte (2000), Cavalcante (2003), Moreira e Candau (2003) e Valente (2005), para citar alguns exemplos.

Há ainda estudos a respeito da formação de professores sob uma abordagem histórica, como os trabalhos de Tanuri (2000) e de Saviani (2009).

Em relação ao tema formação continuada, nos anos de 1990, essa discussão aparece em 17,8\% dos trabalhos e, nos anos 2000, aparece em $21 \%$ das pesquisas. Já o tema identidade e profissionalização docente, que nos anos de 1990 aparecem em 10,2\% dos trabalhos, ganha força nos trabalhos apresentados nos anos 2000, com 41\% das apresentações.

Andrade (2007) explica também que, em sua investigação, 9\% dos trabalhos foram classificados como "outros", e"focalizaram questões, desde a organização curricular ou a inclusão de questões ambientais no ensino médio até um estudo da Revista Brasileira de Educação Física e Desporto, a educação na imprensa escrita ou a formação do cidadão" (ANDRADE, 2007, p. 46). 
Os estudos apresentados por André (2002), Lima (2003), Andrade (2007, apud BRZEZINSKI; GARRIDO, 2001; BRZEZINSKI, 2009) confirmam a quase que total inexistência de estudos sobre a formação de professores para as áreas técnicas, em especial a engenharia, indicando aí uma necessária investigação.

A par desse quadro é possível apreender que a formação de professores para atuação específica no ensino superior só recentemente é objeto de estudo tanto no Brasil quanto em Portugal.

Ao discutirmos como um engenheiro se torna professor, cabe primeiramente definir o que é ser professor no ensino superior. Já há muito se fala e discute sobre a formação de professores para o ensino superior, posto que para além de ser essa uma questão que ainda permanece provocativa, dela derivam aspectos que remetem à permanente vinculação da escola, aqui compreendida como espaço educativo por excelência, com a sociedade.

Ninguém questiona que para ser professor universitário o conhecimento da área específica é uma exigência que poderíamos designar de quase natural, porém há muito que esse conhecimento específico não é mais suficiente. Cada vez mais os desafios que adentram as salas de aulas obrigam os professores a ir além das suas áreas específicas, vinculando a ação docente de forma cada vez mais profunda com os conhecimentos pedagógicos, psicológicos, sociológicos e etc.

Historicamente os professores universitários tem sido considerados somente a partir do domínio de sua área específica, ou seja os melhores professores são sempre os que detêm maior conhecimento sobre o objeto ou tema que vão ensinar.

E como a profissão de professor sempre esteve ligada a ideia de sacerdócio, a aceitação de vocação é também dominante. Talvez isso se dê pelo fato de que todos temos experiência docente, afinal, todos nós tivemos professores em nossas trajetórias escolares e como imitação ou negação, várias pesquisas apontam, escolhemos e moldamos nossa ação pedagógica pelos modelos de professores que tivemos. Ou para imitá-los, ou para negá-los.

Essa imitação ou negação pode ser considerada como o conhecimento pedagógico tácito que todos os professores possuem, mas que no entanto não é mais suficiente para enfrentar os desafios propostos cotidianamente nas salas de aula. 
Considerando que ser professor, dentro da perspectiva dialética, é ser um trabalhador intelectual cuja especificidade é a ação pedagógica, compreendida em suas múltiplas facetas, é preciso considerar o contexto social em que os professores atuam.

A compreensão dessa questão é fundamental para o entendimento do trabalho do professor, pois nos cursos de formação de professores, assim como em vários cursos de formação profissional, o que se observa é que a formação acontece para uma sociedade (escola) idealizada, segundo o ideário liberal. Daí a razão por que em nossa sociedade a expressão "na prática a teoria é outra" ter uma conotação de desmerecimento da teoria e não de entendimento de que a teoria não pode ser sinônimo de prática uma vez que sua complexidade se deixa apreender apenas parcialmente pelo pensamento humano.

Segundo Caldas (2007) um dos aspectos que aparece para os professores como uma causa do sentimento de desistência é a constatação de que sua atividade docente não Ihe possibilita a realização humana plena.

Sensação semelhante é descrita por Lopes (2008), quando ao investigar as trajetórias de formação de professores do 1 CEB afirma "Mas, no percurso profissional, imperam os sentimentos de frustração e de estagnação, dadas as condições de trabalho (isolamento e ausência de inovação), mas também se destaca a luta pela sobrevivência intelectual e pela manutenção do sonho." (LOPES, 2007, p.22)

Cabe também lembrar outra questão fundamental que diz respeito ao entendimento de que o trabalho do professor sendo um trabaIho intelectual pode ser considerado como um trabalho não material, pois o produto não se separa do produtor e, por isso, não produz resultados materiais tangíveis. Contudo, por ser não material, esse trabalho não é completamente frustrante, pois consegue estabelecer para o docente um espaço de liberdade e realização verificável por meio do sentimento de realização profissional e da capacidade de resistência, apontada por Caldas (2007), no Brasil, e Lopes (2007), em Portugal, como capacidade de permanência na atuação docente. Segundo essas autoras, é preciso se entender também a formação dos professores sob a perspectiva da profissionalização docente enquanto dimensão dialética, que contém em si as dimensões de resistência e desistência enquanto próprias de cada professor em diferentes momentos da vida pessoal e profissional. Isso porque cada professor enfrenta, ao longo de sua vida profissional, 
momentos de desânimo e momentos de realização e de desenvolvimento profissional.

\section{Metodologia}

\section{Apresentação do estudo}

Metodologicamente, a pesquisa foi estruturada segundo a consideração do fenômeno - a trajetória de construção das identidades profissionais - como parte da totalidade que é constituída. $O$ entendimento dessa categoria, o fenômeno enquanto parte da totalidade, pressupõe a busca da superação das aparências, buscando-se a compreensão das múltiplas determinações que configuram tal processo.

Assim, opta-se pela construção do quadro categorial valendo-se de entrevistas, sempre destacando o caráter inicial dessa elaboração como contribuição e ponto de partida para estudos mais aprofundados. A entrevista que, enquanto método de pesquisa, tem como principal objetivo a compreensão dos sujeitos entrevistados dentro do contexto histórico e social onde se encontram pois "a entrevista é um dos mais poderosos meios para se chegar ao entendimento dos seres humanos e para a obtenção de informações nos mais diversos campos" (AMADO; FERREIRA, 2013, p. 207).

Investigou-se a trajetória pedagógica dos profissionais formados em engenharia, considerando-se como indicadores metodológicos da pesquisa o delineamento formatado por Lopes et all (2014).

Dessa forma foi possível analisar os seguintes aspectos:

- Motivação inicial que levou os engenheiros a ingressarem na função/carreira docente.

- Trajetórias iniciais de formação e a ocorrência ou não de formação pedagógica.

- Necessidade ou não dessa formação.

- Dificuldades enfrentadas e as possibilidades vislumbradas no exercício da docência.

- Reconhecimento próprio do "ser docente", ou seja, se esses profissionaisconsideram-se realizados e felizes enquanto professores ou não.

Para o tratamento das entrevistas, recorreu-se à análise de conteúdo que, segundo Bardin (1977, p. 14), “pode ser uma análise dos 'sig- 
nificados', embora possa ser também uma análise dos 'significantes'", o que implica na permanente necessidade de compreensão do fenômeno enquanto movimento, que se altera a cada momento, sendo modificado e modificando os atores envolvidos constantemente. Essa abordagem, dentro da perspectiva da pesquisa qualitativa, possibilita o estudo da história dos sujeitos e suas relações, bem como de suas representações, crenças, percepções e das opiniões, produto das interpretações que os seres humanos fazem de como vivem, constroem seus artefatos e a si mesmos, sentem e pensam (TURATO et al, 2008).

\section{Contextos e participantes da pesquisa}

A pesquisa no Brasil foi realizada em duas instituições distintas. Uma é uma Universidade Acadêmica e a outra é uma Universidade Corporativa. Para a pesquisa realizada nesse momento optamos por considerar os dados referentes apenas à Universidade Acadêmica pois apesar da nomenclatura é equivalente à Universidade Portuguesa.

Assim sendo, na sequência apresentamos os sujeitos investigados, utilizando-se a seguinte denominação para os sujeitos: BR, para os professores da Universidade Brasileira e PT para os professores da Universidade Portuguesa.

Foram entrevistados 10 professores da BR e 14 da PT.

Os professores brasileiros foram indicados pelo coordenador do curso de graduação em Engenharia Elétrica obedecendo-se os seguintes critérios:

- Formação em engenharia elétrica.

- Início de atuação profissional como engenheiro e não como professor.

- Conceito excelente de atuação docente, segundo a coordenação e as avaliações dos alunos realizadas nos dois últimos anos.

Cabe destacar que das indicações feitas pelo coordenador da BR, apenas 2 eram mulheres, situação compreendida pelo fato de a engenharia elétrica ser uma área ainda predominantemente dominada por profissionais do gênero masculino. As professoras não foram entrevistadas em razão de sua indisponibilidade de tempo no período da pesquisa, fato que dá margem para uma investigação, mais pormenorizada e em momento oportuno, da atuação de mulheres docentes na engenharia. 
Na PT os professores foram convidados a participar da pesquisa de forma espontânea seguindo apenas o critério de formação em engenharia elétrica e aqui também foi possível verificar o número reduzido de mulheres que atuam na área.

Apenas uma professora participou da pesquisa.

Quanto à faixa etária, nas duas instituições, os entrevistados têm entre 38 e 67 anos. Desses, foram entrevistados 6 profissionais com idade entre 38 e 45 anos, 10 na faixa etária entre 45 e 60 anos, e 8 entre 61 e 67 anos.

Na tabela 1 apresenta-se o número de docentes participantes por faixa etária e o seu tempo de atuação.

Tabela 1 - Número de professores entrevistados por faixa etária e tempo de atuação

\begin{tabular}{c|c|c|c|c}
\hline \multirow{2}{*}{ Faixa etária } & \multicolumn{3}{|c}{ Quantidade - Instituição/Tempo de atuação } \\
\cline { 2 - 5 } & \multicolumn{2}{|c}{ BR } & \multicolumn{2}{c}{ PT } \\
& \multicolumn{2}{|c|}{ Universidade Brasileira } & \multicolumn{2}{c}{ Universidade Portuguesa } \\
\hline 38 a 45 anos & 4 & 07 a 12 & 2 & 07 a 18 \\
\hline 46 a 60 anos & 2 & 10 a 15 & 8 & 16 e 20 a 35 \\
\hline 61 a 67 & 4 & 19 a 25 & 4 & 40 a 44 \\
\hline
\end{tabular}

Fonte: Elaborada pelas autoras.

No grupo completo temos, então, 6 profissionais que estão na faixa etária entre 38 a 45 anos tem entre 7 a 18 anos de atuação docente, 10, que estão na faixa etária de 45 e 60 anos, têm de 16 a 35 anos de atuação como docentes e os profissionais que estão na faixa etária de 61 a 67 anos tem como experiência docente de 40 a 44 anos.

Aqui cabem duas observações importantes. Primeiro o fato de que a única professora entrevistada na PT é a única profissional que teve o início de sua carreira docente muito tempo depois de estar formada, dado esse que difere dos outros entrevistados que iniciaram sua carreira docente imediatamente após o término da graduação.

Outro aspecto importante diz respeito ao fato de que é na PT que encontramos os professores com maior tempo de atuação e isso com certeza se deve ao fato de que um dos critérios na seleção dos professores da BR ter sido a experiência profissional anterior a docência. 
Cabe também lembrar que na PT encontramos os professores com idade mais avançada pois as oportunidades de ingresso na carreira universitária tem sido muito escassas, bem como a política de aposentadoria, denominada reforma, que faz com que os mesmos permaneçam em atuação.

Na PT um dos dados que nos chamou a atenção foi o fato de que todos os entrevistados, mesmo o professor com menor tempo de atuação, iniciaram sua atividade docente logo após o final da graduação. Apenas cinco, dos quatorze entrevistados, tiveram experiência em indústria após a graduação, um com seis meses, dois com um ano, dois com dois anos e um com quatro anos de atuação.

Quanto à formação, na BR, foram entrevistados 7 doutores e 3 mestres, já na PT, todos os entrevistados são doutores.

Resumidamente os professores entrevistados apresentam as seguintes características:

Tabela 2 - Caracterização dos professores entrevistados no Brasil

\begin{tabular}{|c|c|c|c|c|c|c|c|c|c|c|}
\hline \multirow{2}{*}{$\begin{array}{c}\text { ENTREVIS- } \\
\text { TADO }\end{array}$} & \multirow{2}{*}{$\begin{array}{c}\text { IDADE } \\
\text { EM } \\
\text { ANOS }\end{array}$} & \multirow{2}{*}{$\begin{array}{l}\text { TEMPO DE } \\
\text { ATUAÇÃO } \\
\text { EM ANOS }\end{array}$} & \multicolumn{3}{|c|}{ EXPERIENCIA DOCENTE } & \multicolumn{5}{|c|}{$\begin{array}{l}\text { FORMAÇÃO } \\
\text { TITULAÇÃO }\end{array}$} \\
\hline & & & $\begin{array}{l}\text { INSTRU- } \\
\text { TOR }\end{array}$ & $\begin{array}{l}\text { ENS. } \\
\text { TÉC }\end{array}$ & $\begin{array}{c}\text { EDUC. } \\
\text { SUP. }\end{array}$ & $\begin{array}{c}\text { ESQUE- } \\
\text { MA I }\end{array}$ & $\begin{array}{c}\text { ESQUE- } \\
\text { MA II }\end{array}$ & $\begin{array}{c}\text { ESP. } \\
\text { /MET. } \\
\text { DE ENS. }\end{array}$ & MEST. & DOUT. \\
\hline 01 & 40 & 12 & $x$ & $x$ & $x$ & $x$ & $x$ & $x$ & $x$ & $x$ \\
\hline 02 & 66 & 19 & & $x$ & & & $\mathrm{x}$ & & & \\
\hline 03 & 46 & 10 & & $x$ & $x$ & $x$ & & $x$ & $x$ & $x$ \\
\hline 04 & 52 & 15 & & $x$ & $x$ & $x$ & $x$ & $x$ & $x$ & $x$ \\
\hline 05 & 43 & 10 & & $x$ & & $x$ & & $x$ & $\mathrm{x}$ & \\
\hline 06 & 38 & 07 & $x$ & $x$ & & $x$ & & & & \\
\hline 07 & 40 & 07 & $x$ & & $x$ & & & & & \\
\hline 08 & 62 & 20 & $x$ & $x$ & $x$ & $x$ & $x$ & & $x$ & $x$ \\
\hline 09 & 67 & 22 & & $x$ & $x$ & $x$ & $x$ & & $x$ & \\
\hline 10 & 65 & 25 & $x$ & $x$ & $x$ & $x$ & $x$ & $x$ & $x$ & $x$ \\
\hline
\end{tabular}

Fonte: Urbanetz, 2011, p.41. 
Tabela 3 - Caracterização dos professores entrevistados em Portugal

\begin{tabular}{|c|c|c|c|c|c|c|}
\hline \multirow{2}{*}{$\begin{array}{l}\text { ENTRE- } \\
\text {-VISTADO }\end{array}$} & \multirow{2}{*}{ IDADE } & \multirow{2}{*}{$\begin{array}{l}\text { TEMPO DE } \\
\text { ATUAÇÃO NO } \\
\text { ENSINO SUPE- } \\
\text { RIOR }\end{array}$} & \multicolumn{2}{|r|}{ ATUAÇÃO ANTERIOR } & \multicolumn{2}{|c|}{$\begin{array}{l}\text { FORMAÇÃO PEDA- } \\
\text { GÓGICA }\end{array}$} \\
\hline & & & SIM & EM QUÊ & SIM & QUAL \\
\hline 01 & 54 & 30 & & & $x$ & $\begin{array}{c}\text { Variadas e } \\
\text { projeto da } \\
\text { Universidade* }\end{array}$ \\
\hline 02 & 60 & 35 & & & $\mathrm{x}$ & Variadas \\
\hline 03 & 52 & 16 & & & $x$ & $\begin{array}{l}\text { Projeto da } \\
\text { Universidade }\end{array}$ \\
\hline 04 & 57 & 20 & $x$ & $\begin{array}{l}\text { Empresa de infor- } \\
\text { mática } \\
\text { (4 anos) }\end{array}$ & & \\
\hline 05 & 53 & 30 & & & & \\
\hline 06 & 63 & 42 & & & $x$ & $\begin{array}{l}\text { Seminários } \\
\text { ocasionais }\end{array}$ \\
\hline 07 & 49 & 24 & & & $x$ & Variadas \\
\hline 08 & 38 & 07 & $x$ & $\begin{array}{l}\text { Empresa de distri- } \\
\text { buição de energia ( } 2 \\
\text { anos) }\end{array}$ & & \\
\hline 09 & 43 & 18 & & & $x$ & $\begin{array}{c}\text { Projeto da } \\
\text { Universidade } \\
\text { e IGIP Alema- } \\
\text { nha** }\end{array}$ \\
\hline 10 & 51 & 28 & $x$ & $\begin{array}{l}\text { No início, em paralelo } \\
\text { a universidade, na } \\
\text { indústria metal-mecâ- } \\
\text { nica ( } 1 \text { ano) }\end{array}$ & $x$ & Variadas \\
\hline 11 & 61 & 40 & $x$ & $\begin{array}{l}\text { Empresa de engenha- } \\
\quad \text { ria ( } 1 \text { ano) }\end{array}$ & $x$ & Alguma \\
\hline 12 & 65 & 43 & & & $\mathrm{x}$ & Pouca \\
\hline 13 & 56 & 34 & $x$ & Indústria (6 meses) & & \\
\hline 14 & 66 & 44 & & & $\mathrm{X}$ & Pouca \\
\hline
\end{tabular}

Fonte: Elaborada pelas autoras. Programa ofertado na Universidade. ${ }^{4}$

No Brasil, a formação de professores para as chamadas áreas técnicas iniciou-se em 1984 com a criação do Programa Institucional de Capacitação Docente, e em 1985 iniciaram-se os cursos emergenciais para a formação de professores, oferecidos pelo MEC, conhecidos como

4 Programa de Certificação Pedagógica ofertada a engenheiros pela International Society for Engineering Education and modern engineering pedagogy http://www.igip.org/igip/ 
Esquema I e Esquema II, objetivando a formação para o ensino profissional em nível médio e superior, que foram criados a partir da Portaria 432 de 19/07/71.

Segundo Leite (2010, p. 87):

Os cursos emergenciais Esquema I e Esquema II foram criados pelo MEC para suprir a falta de professores do ensino técnico habilitados em nível superior no Brasil. Os cursos do Esquema I traziam a complementação pedagógica aos portadores de diploma de nível superior. No esquema II, os cursos eram direcionados aos técnicos diplomados e neles estavam incluídas disciplinas pedagógicas existentes no Esquema I e as de conteúdo técnico específico. Desde 1984, o Cefet-PR passou a ofertar esses cursos em convênio com instituições de ensino federais, estaduais e particulares.

Mello (1997), ao investigar o impacto do Esquema I e Esquema II na formação e atuação dos professores do Centro Federal de Educação Tecnológica do Paraná (Cefet-PR), apontou que tais cursos contribuíram significativamente para apenas uma parcela restrita de professores.

Por essa razão é que apresentamos na tabela referente aos professores brasileiros a indicação dos Esquemas I e II visto serem esses os cursos de formação ofertados na época.

Em Portugal, observamos que apesar de todos os professores afirmarem ser necessária a formação pedagógica, apenas três participaram ativamente de uma das ofertas mais consistentes feita pela Instituição.

Apenas um professor entrevistado na PT afirmou nunca ter sido ofertado um curso ou evento de formação pedagógica. Os outros professores que não fizeram nenhuma formação afirmaram não ter tido tempo no momento da oferta dessa formação.

\section{Descrição e discussão dos resultados da análise}

A análise tem em conta as seguintes categorias:

- A motivação para ingresso na carreira docente.

- Mudanças nas trajetórias iniciais de atuação.

- Dificuldades e possibilidades encontradas no exercício da docência. 
- Existência e necessidade de formação pedagógica.

- Sentimento de realização pela docência

Motivação - a possibilidade de investigar

Embora o início da atuação dos professores da BR tenha se dado em contextos industriais, todos os entrevistados afirmaram ter feito da docência uma opção consciente. Alguns por convite, mas todos, sem exceção escolheram ser professores. Dois professores da PT afirmaram ter feito essa escolha por que na época professor não precisava ir para a guerra, e todos afirmaram que a possibilidade de investigação foi um motivador fundamental para essa escolha.

André (1995), Bogdan \& Biklen (1994), Nóvoa (2007) e Zeichner (1993) são apenas alguns dos muitos autores que enfatizam a importância da pesquisa tanto para a atuação, quanto para o desenvolvimento profissional dos professores. Vieira (2014) indica que quando os professores investigam suas próprias práticas qualificam o desenvolvimento da atividade pedagógica. Isso pode ser verificado na pesquisa aqui apresentada.

Segundo os entrevistados a possibilidade de desenvolver projetos de investigação é um dos aspectos que mais Ihes dá satisfação na atuação docente e nas palavras do professor PT 5 " $50 \%$ ensinar e $50 \%$ pesquisar é o que há de melhor!"

Essa também é a razão principal para que os entrevistados das duas universidades tenham escolhido a docência como profissão. Segundo eles, a possibilidade de estar permanentemente investigando é um desafio realizador, tanto que esses mesmos professores apontam como uma das maiores dificuldades atuais, a diminuição dos financiamentos de pesquisa imposta pelos governos dos dois países.

Mudanças: menor financiamento da investigação; mais recursos tecnológicos, novas características dos estudantes e aprendizagem pessoal

A diminuição do financiamento da investigação é um dos aspectos que os entrevistados apontam como uma mudança ocorrida nos últimos anos. A dificuldade de financiamento para projetos de pesquisa 
tem se tornado uma constante em várias instituições de ensino, tanto no Brasil quanto em Portugal.

Para além disso os professores apontam as mudanças nos recursos tecnológicos, que são claramente visíveis em todos os aspectos juntamente com a mudança de comportamento do estudante em sala de aula.

$\mathrm{Na}$ fala dos professores: "antes era só falatório, livro..., hoje podemos verificar qualquer informação imediatamente na internet, no entanto não me parece que eles (estudantes) estejam a aproveitar toda essa informação" (PT 11).

Em relação ao comportamento dos estudantes, outro professor faz uma colocação também interessante: "eles (estudantes) têm muitas demandas, tanto de trabalho, como das redes sociais. As vezes tenho a impressão de que estão a se perder! (PT 6)

Essa questão comportamental é também apontada pelos professores no Brasil que afirmam receber a cada ano alunos com mais e mais dificuldades de leitura, raciocínio, concentração e etc.

Poderíamos inferir que esse fenômeno ocorre em função de um maior acesso ao ensino superior das camadas populacionais com uma escolarização empobrecida porém em função da alta competitividade para acesso ao curso superior de engenharia, tendemos a pensar que isso está muito mais ligado aos processos sociais de cultura midiática.

Além desses, os professores apontam uma mudança significativa na sua própria maneira de ensinar. Todos são unânimes em afirmar que muita coisa mudou na forma como ensinavam.

PT 3 afirma que "após o choque inicial" percebeu que era necessário um outro caminho, foi então em busca de formação e auxílio. Mesmo assim, afirma que ainda hoje sente que não consegue perceber se todos os estudantes estão a aprender efetivamente.

BR 9 afirmou que iniciou "do jeito que tinha aprendido" mas que "hoje não me importo mais em falar o tempo todo, sei que eles precisam de tempo pra pensar e resolver os exercícios".

Essa também é a perspectiva do professor PT 10 que aponta claramente a superação da ideia de que basta falar para que os estudantes aprendam e ainda do professor PT 8 quando ele diz que "hoje me sinto mais a vontade com os alunos". 
Dificuldades: novos estudantes; desorganização administrativa e burocracia que impedem melhor dedicação à docência

Em termos de dificuldades específicas os professores apontam além do aspecto comportamental dos alunos, a "desorganização administrativa" (PT 2), a "burocracia" (PT 6) e "acompanhar de outra maneira os alunos que não aprendem" (PT 11).

Exatamente os mesmos aspectos apontados pelos professores brasileiros que afirmam: "temos muitas demandas administrativas que atrapalham" (BR 5), "cada vez temos menos tempo pra estudar e pesquisar" (BR 2)

Essas dificuldades aparecem cada vez mais aos professores em função da forma como as instituições vão sendo forçadas a se organizarem com menos recursos, menos pessoal e um maior número de estudantes matriculados. As demandas administrativas assolam cada vez mais o trabalho docente ocasionando mais frustração indicada na fala do professor PT 11 que não vê como poderia acompanhar melhor os estudantes que tem dificuldade na sua disciplina.

\section{Formação pedagógica}

Dos vinte e quatro entrevistados apenas um afirmou categoricamente não sentir falta de formação pedagógica, os outros afirmaram que essa formação com certeza auxilia o desenvolvimento do trabalho em sala de aula.

Nos professores brasileiros entrevistados que fizeram a formação nos cursos chamados Esquema I e Esquema II observou-se a mesma perspectiva apontada no estudo de Mello (1997), ou seja, dos dez entrevistados, apenas um apontou o curso de formação pedagógica como um curso que auxiliou na sua formação e atuação docente. Todos os outros docentes afirmaram que o Esquema I não apresentou melhorias. Contudo, ressaltaram que a forma de desenvolvimento do curso foi responsável pela constatação de que ainda necessitavam de aprendizagem pedagógica.

Talvez seja o tipo de formação que aqui está em causa. O professor PT 2, por exemplo, ressalta que "o academicismo da pedagogia descolado da realidade não nos serve de nada".

Os estudos apontam que uma das maiores dificuldades na formação de professores tem sido a não vinculação com a realidade. Ou 
seja, os professores, alunos nesses cursos, não conseguem perceber a vinculação do que se fala e do que se faz com as respectivas realidades de suas salas de aula.

Korthagen, Loughram \& Russel ao discutirem a formação de professores em abordagens orientadas ora para a investigação, ora para a prática, questionam: "poderemos integrar estas duas perspectivas para chegar a uma pedagogia de formação de professores que seja, simultaneamente, empiricamente baseada e praticamente orientada?" (Korthagen, Loughram \& Russel in Lopes, 2013, p.22)

Essa e outras questões são constantes na discussão sobre a forma mais adequada para a formação de professores em todos os níveis e modalidades de ensino.

Os autores apresentam alguns princípios que julgam ser essenciais para a formação de professores. Esses princípios basicamente dizem respeito à necessidade da aprendizagem através da experiência, alternando prática e teoria nos cursos de formação inicial, da reflexão sobre essa experiência e da interação com os outros além da necessária investigação permanente sobre a sua própria prática.

Em nossa investigação o professor PT 5 ficou emocionado durante a entrevista e constatou que nunca tinha parado para pensar sobre a sua trajetória como docente e mesmo considerando que tem um bom desempenho acredita que momentos que lhe proporcionassem esse tipo de reflexão, com certeza, auxiliariam o processo educativo de forma constante.

Isso mostra como as mudanças que vão ocorrendo durante a carreira docente promovem constantemente a aprendizagem pessoal e como essas aprendizagens modificam a ação didática desenvolvida.

\section{Realização pessoal pela docência}

Em termos de realização, todos os professores são unânimes e categóricos em afirmar que sentem-se completamente realizados enquanto docentes. Mesmo os professores que escolheram a docência pois isso Ihes afastava da obrigação de servir na guerra, afirmam que não se arrependem, nem trocariam de profissão.

Os professores brasileiros e portugueses que tiveram outra experiência profissional fazem também essa afirmação com a mesma intensidade dos professores portugueses que sempre foram professores. 
Para alguns isso pode parecer "a resposta que a entrevistadora quer ouvir" porém os olhos quase nunca mentem. E os olhos desses professores brilharam várias vezes durante as entrevistas o que nos faz crer que realmente, apesar das dificuldades, todos sentem-se plenamente comprometidos como docentes.

Percebe-se que a trajetória dos professores da área da engenharia nas Universidades pesquisadas no Brasil e em Portugal têm muito em comum tanto em termos de formação acadêmica quanto em função dos desafios apresentados.

Professores brasileiros e portugueses enfrentam os mesmos desafios em relação a financiamento de pesquisas, burocracia, etc, e também questionam-se permanentemente sobre as aprendizagens de seus alunos.

Esses desafios marcam significativamente sua ação didática e coincidem com as preocupações de vários autores que discutem alternativas para a formação de professores.

A preocupação com a formação de mais e melhores professores tem aparecido em vários países e muitas vezes apontada como "a" única questão a ser resolvida diante dos problemas educacionais e sociais vivenciados na atualidade.

Percebe-se claramente entre os pesquisadores que as angústias são comuns apesar dos países terem características de desenvolvimentos diferentes. Em especial a preocupação com a articulação entre teoria e prática, a crescente burocratização, as avaliações cada vez mais padronizadas, o ranqueamento, a precarização do trabalho docente (com poucas exceções) aparecem em pesquisas no mundo todo.

Vale ressaltar que os professores durante as entrevistas também indicam, de forma generalizada, que é preciso compreender a escola como um espaço para pensar a realidade social, cada vez mais desafiadora.

Segundo os estudiosos da área, isso é possível pela via da fundamentação teórica, pois à escola cabe o trabalho com o conhecimento recontextualizado (MOREIRA, 2008), ou seja, o conhecimento conforme o entendimento da linguagem escolar. Nessa perspectiva, cabe explicar que o trabalho com o conhecimento científico é função primordial da escola, ao passo que a função do professor é assumir essa dimensão em toda a sua complexidade.

Assim se explicita como a formação pedagógica pode contribuir na formação dos professores ampliando as possibilidades dos professores de pensarem as suas ações para além das indicações didáticas. 


\section{Conclusões}

Essa investigação procurou demonstrar a trajetória profissional de professores do ensino superior em duas Universidades, uma brasileira e outra portuguesa discutindo a questão da formação pedagógica necessária a essa atuação.

A pesquisa demonstrou que nas duas Universidades apesar do início de carreira ter ocorrido de forma diferente para alguns, a motivação inicial para o ingresso na docência foi a mesma: a possibilidade de desenvolver projetos de investigação.

A investigação é um dos fatores de realização dos entrevistados, mas também de preocupação e angústia diante do quadro econômico dos dois países. Os professores vivenciam cada vez mais dificuldades com o financiamento de suas pesquisas e de implantação de novos projetos.

Os professores apontam mudanças significativas em suas práticas, especialmente em relação à preocupação com a aprendizagem dos alunos e o uso cada vez mais necessário das novas tecnologias educacionais e a consciência de que é preciso aprender continuamente pois os alunos trazem para as salas de aula comportamentos e problemas bastante diferenciados.

A pesquisa mostrou ainda que a formação pedagógica necessária a esses professores precisa auxiliá-los diante das demandas dos alunos, não apenas como "receitas" que devem ser usadas indistintamente.

No ensino superior tem se percebido que não basta ao professor saber apenas o conteúdo específico que será trabalhado. As mudanças apontadas nos estudos e também pelos entrevistados indicam a abertura dos docentes, e a necessidade, de uma formação que discuta a multiplicidade de aspectos presentes nas relações pedagógicas.

O início da formação técnica dos professores de engenharia nas antigas oficinas de artes e ofícios indica o germe de formação dos profissionais técnicos, bem como de seus professores. Esses professores eram os mestres de ofício, ou seja, profissionais que tinham como meta a difusão de seu conhecimento. Não eram, necessariamente, aqueles que sabiam ensinar, visto que o "método" de ensino era a simples demonstração seguida de imitação.

Interessante é que, até hoje, essa é uma característica marcante da formação nos cursos das áreas técnicas. A pesquisa realizada no 
Brasil (URBANETZ, 2011) indicou que os professores não são exclusivamente professores, mas normalmente profissionais formados em áreas específicas de conhecimento. Já em Portugal a pesquisa revelou a ação docente como escolha e atuação imediata após a graduação. E ainda que permaneça a preocupação com o conteúdo da própria disciplina, esses professores apontam o valor e a necessidade de uma formação pedagógica consistente que os auxilie durante o percurso didático.

Os estudos sobre a formação de professores para os cursos das áreas técnicas, tecnológicas e especificamente para o ensino superior confirmaram que, para esses profissionais, a preocupação com a formação docente permanece como um desafio a ser enfrentado.

Ferenc (2005), ao investigar a forma como o professor universitário aprende a ensinar, juntamente com Barbosa (2001), que explicita o discurso pedagógico na educação tecnológica, confirmam, entre outros autores, o que se afirma sobre a formação dos professores do ensino superior, principalmente dos docentes das áreas chamadas exatas: não se exige formação pedagógica, o que gera um elemento complicador do processo educativo, visto o consenso de que este necessita de procedimentos específicos, dada a sua complexidade.

Decorre então que a formação do professor para o ensino superior das áreas técnicas demanda a criação de propostas que enfrentem a questão de como esses profissionais podem ser formados levando-se em conta o percurso já realizado e o desempenho atual, as diferenças inerentes ao tempo de experiência de cada um, os fatores institucionais, etc.

Considerando-se que na atualidade as capacidades psicofísicas de imitação e repetição já não são suficientes para a formação dos profissionais, o professor precisa ser um profissional que, além do conhecimento técnico de sua área, consiga dominar tal conhecimento sob um viés científico e também pedagógico, a fim de garantir um processo de aprendizagem efetivo aos seus alunos.

Cabe portanto considerar que a formação de professores não pode se pautar apenas na compreensão das metodologias enquanto técnicas sistematizadas em manuais. Isso porque, ao se pautar a formação apenas no "como fazer", perde-se o entendimento do "por que" fazer, e dos diversos contextos em que "esse fazer" se insere, bem como dos novos e diversos conhecimentos que demanda. 


\section{Referências}

AMADO, João, FERREIRA, Sonia. A entrevista na investigação em educação. In AMADO, João (coord.)Manual de investigação qualitativa em educação.Coimbra: Imprensa da Universidade de Coimbra, 2013.

ANDRADE, Roberta Rotta Messias de. Pesquisas sobre formação de professores: uma comparação entre os anos 90 e 2000. In: REUNIÃO ANUAL DA ANPED, 30., 2007, Caxambu, MG.Programa e Resumos [da] 30. Reunião Anual da Associação de Pós-Graduação e Pesquisa em Educação. [São Paulo]: ANPED - Associação Nacional de Pós-Graduação e Pesquisa em Educação, 2007.

ANDRÉ, Marli; ROMANOWSKI, Joana P. O tema formação de professores nas dissertações e teses (1990-1996). In: ANDRÉ, Marli.Formação de professores no Brasil (1990-1998).Brasília: MEC, 2002. p. 17-156.

ANDRÉ, Marli E. D. Afonso de.Etnografia da prática escolar. Campinas: Papirus, 1995.

BOGDAN, Robert; BIKLEN, Sari.A investigação qualitativa em educação: uma introdução à teoria e aos métodos.Porto, Portugal: Porto Editora, 1994.

BARBOSA, Maria Núbia.O discurso pedagógico na educação tecnológica.Dissertação (Mestrado em Tecnologia) - Universidade Tecnológica Federal do Paraná, Curitiba, 2001.

BARDIN, Laurence.Análise de conteúdo. Lisboa: Edições 70, 1977.

BRZEZINSKI, Iria; GARRIDO, Elsa. Análise dos trabalhos de GT Formação de Professores: o que revelam as pesquisas do período 1992-1998.Revista Brasileira de Educação, São Paulo, n. 18, p. 82-100, set./dez. 2001.

BRZEZINSKI, Iria. Pesquisa sobre formação de profissionais da educação no GT 8/Anped: travessia histórica.Formação Docente, Belo Horizonte, v. 1, n. 1, p. 71-94, ago./dez. 2009. Disponível em: <http://formacaodocente. autenticaeditora.com.br>.

CALDAS, Andrea do Rocio.Desistência e resistência no trabalho docente:um estudo das professoras e professores do Ensino Fundamental da Rede Municipal de Educação de Curitiba. 173 f. Tese (Doutorado em Educação) - Universidade Federal do Paraná, Curitiba, 2007. 
CARVALHO, Janete Magalhães. O não-lugar dos professores nos entre lugares de formação continuada.Revista Brasileira de Educação, São Paulo, n. 28, p. 96-107, jan./abr. 2005.

CAVALCANTE, Lucíola Inês Pessoa. Formação de professores na perspectiva do movimento dos professores indígenas da Amazônia. Revista Brasileira de Educação, São Paulo, n. 22, p. 14-24, jan./abr. 2003.

DUARTE, Newton. As pedagogias do "aprender a aprender" e algumas ilusões da assim chamada sociedade do conhecimento.Revista Brasileira de Educação, Rio de Janeiro, n. 18, p. 35-40, set./dez. 2001.

DUARTE, Newton. A contradição entre a universalidade da cultura humana e o esvaziamento das relações sociais: por uma educação que supere a falsa escolha entre etnocentrismo ou relativismo cultural. Educação e Pesquisa, São Paulo, v. 32, p. 607-618, 2006.

FERENC, Alvanize Valente Fernandes.Como o professor universitário aprende a ensinar?Um estudo na perspectiva da socialização profissional. Tese (Doutorado em Educação) - Universidade Federal de São Carlos, São Carlos, 2005.

KENSKI, Vani Moreira. Novas tecnologias: o redimensionamento do espaço e do tempo e os impactos no trabalho docente.Revista Brasileira de Educação, São Paulo, n. 8, p. 58-71, mai./ago. 1998.

KRAMER, Sônia. Leitura e escrita de professores: da prática de pesquisa à prática de formação.Revista Brasileira de Educação, São Paulo, n. 7, p. 19-41, jan./abr. 1998.

KUENZER, Acácia Zeneida. Educação Profissional: categorias para uma nova pedagogia do trabalho.Boletim Técnico do Senac, Rio de Janeiro, v. 25, n. 2, maio/ago. 1999.

KUENZER, Acácia Zeneida. As relações entre conhecimento tácito e conhecimento científico a partir da base microeletrônica: primeiras aproximações.Educar, Curitiba, ed. especial, p. 43-69, 2003.

KUENZER, Acácia Zeneida. A educação profissional nos anos 2000: a dimensão subordinada das políticas de inclusão.Educação \& Sociedade, Campinas,SP, v. 27, n. 96,2006. Disponívelem:<http://www.scielo.br/scielo.php?script=sci_ arttext\&pid=S0101-73302006000300012\&lng=pt\&nrm=iso >. 
KUENZER, Acácia Zeneida. Formação de professores para a educação profissional e tecnológica: perspectivas históricas e desafios contemporâneos. In: INEP.Formação de professores para educação profissional e tecnológica. Brasília: Instituto Nacional de Estudos e Pesquisas Educacionais Anísio Teixeira, 2008. (Coleção Educação Superior em Debate, v. 8).

LEITE, José C. C. (Org.).UTFPR: uma história de 100 anos. Curitiba: Ed. UTFPR, 2010.

LELIS, Isabel. Profissão docente: uma rede de histórias.Revista Brasileira de Educação, São Paulo, n. 17, p. 40-49, maio/ago. 2001.

LIMA, E. F. et al. Análise crítica dos trabalhos apresentados no GT 8 no período 1999-2003. In: REUNIÃO ANUAL DA ANPED, 26., 2003, Caxambu, MG.Programa e Resumos [da] 26. Reunião Anual da Associação de Pós-Graduação e Pesquisa em Educação. [São Paulo]: ANPED - Associação Nacional de Pós-Graduação e Pesquisa em Educação, 2003.

LOPES, Amélia (Org.) 2007.De uma escola a outra - temas para pensar a formação inicial de professores. Porto: Afrontamento/CIIE.

LOPES, Amélia (Org.) 2013. Formação inicial de professores e de enfermeiros: identidades e ambientes. Porto:Livpsic, 2013.

LOPES, Amélia, CAVALCANTE, Maria Auxiliadora da Silva, OLIVEIRA Dalila Andrade; HYPÓLITO, Álvaro Moreira (Orgs.)Trabalho Docente e Formação: Políticas, Práticas e Investigação: Pontes para a mudança. CIIE - Centro de Investigação e Intervenção Educativas, 2014.

MANZANO, Cinthia Soares. A formação de professores na Revista Brasileira de Educação (1995-2005): uma breve análise. In: REUNIÃO ANUAL DA ANPED, 31., 2008, Caxambu, MG. Programa e Resumos [da] 31.Reunião Anual da Associação de Pós-Graduação e Pesquisa em Educação. [São Paulo]: ANPED - Associação Nacional de Pós-Graduação e Pesquisa em Educação, 2008.

MELLO, Diene Eire de. (1997)O esquema I e sua contribuição para a prática docente no Centro Federal de Educação Tecnológica do Paraná. Dissertação (Mestrado em Tecnologia) - Centro Federal de Educação Tecnológica do Paraná, Curitiba, 1997. 
MENEZES, Luis Carlos de. Trabalho e visão de mundo: ciência e tecnologia na formação de professores. Revista Brasileira de Educação, São Paulo, n. 7, p. 75-81, jan./abr. 1998.

MONTE, Nietta Lindenberg. E agora, cara pálida? Educação e povos indígenas, 500 anos depois.Revista Brasileira de Educação, São Paulo, n. 15, p. 118-133, set./dez. 2000.

MORAES, Maria Célia M. de (Org.).lluminismo às avessas: produção do conhecimento e políticas de formação docente. Rio de Janeiro: DP\&A, 2003.

MOREIRA, Antonio Flavio Barbosa; CANDAU, Vera Maria. Educação escolar e cultura(s): construindo caminhos.Revista Brasileira de Educação, São Paulo, n. 23, p. 156-168, mai./ago. 2003.

MOREIRA, Antonio Flávio Barbosa; CANDAU, Vera Maria.Indagações sobre currículo:currículo, conhecimento e cultura. Brasília: MEC, 2008

MOREIRA, Plínio Cavalcanti; DAVID, Maria Manuela Martins Soares. O conhecimento matemático do professor: formação e prática docente na escola básica.Revista Brasileira de Educação, São Paulo, n. 28, p. 50-61, jan./abr. 2005.

MUSATTI, Tullia. Programas educacionais para a pequena infância na Itália.Revista Brasileira de Educação, São Paulo, n. 24, p. 66-77, set./ dez. 2003.

NÓVOA, Antonio. Vidas de Professores. Porto: Porto, 1991 e 2007.

NÓVOA, Antonio. (coord.) Os professores e sua formação. Lisboa: Dom Quixote, 1992.

Perrenoud, Philippe.Dez novas competências para ensinar: convite à viagem. Porto Alegre: Artmed, 2000.

Perrenoud, Philippe. A prática reflexiva no ofício de professor: profissionalização e razão pedagógicas. Porto Alegre: Artmed, 2002.

PRETTO, Nelson de Luca. Formação de professores exige rede.Revista Brasileira de Educação, São Paulo, n. 20, p. 121-131, mai./ago. 2002.

RAMOS, Marise Nogueira.A pedagogia das competências: autonomia ou adaptação? São Paulo: Cortez, 2001.

SCHON, Donald A. Formar professores como profissionais reflexivos. In: 
NÓVOA, Antonio.Os professores e sua formação. Lisboa: Dom Quixote, 1992.

SCHON, Donald A.Educando o profissional reflexivo: um novo design para o ensino e a aprendizagem. Porto Alegre: Artmed, 2000.

SILVA JUNIOR, João dos Reis. Reformas do Estado e da educação e as políticas públicas para a formação de professores a distância: implicações políticas e teóricas.Revista Brasileira de Educação, São Paulo, n. 24, p. 78-94, set./dez. 2003.

SILVA, Marilda da. O habitus professoral: o objeto dos estudos sobre o ato de ensinar na sala de aula.Revista Brasileira de Educação, São Paulo, n. 29, p. 152-163, maio/ago. 2005.

SOUSA, Cynthia P. et al. Memória e autobiografia: formação de mulheres e formação de professoras.Revista Brasileira de Educação, São Paulo, n. 2, p. 61-76, mai./ago. 1996.

TANURI, Leonor Maria. História da formação de professores.Revista Brasileira de Educação, São Paulo, n. 14, p. 61-88, mai./ago. 2000.

TARDIF, Maurice.Saberes docentes e formação profissional. Petrópolis, RJ: Vozes, 2002.

TURATO, E. R. et al. Amostragem por saturação em pesquisas qualitativas em saúde: contribuições teóricas. Cadernos de Saúde Pública, Rio de Janeiro, v. 24, n.1, p. 17-27, jan. 2008.

URBANETZ, Sandra Terezinha. A constituição do docente para a educação profissional. Tese (Doutorado em Educação) - Universidade Federal do Paraná, Curitiba, 2011.

VALENTE, Ana Lucia. Ação afirmativa, relações raciais e educação básica. Revista Brasileira de Educação, São Paulo, n. 28, p. 62-76, jan./abr. 2005.

VARGAS, Sonia Maria de. Processos de formação e aprendizagem no meio rural: o continuum família-escola. Revista Brasileira de Educação, São Paulo, n. 24, p. 95-106, set./dez. 2003.

VIEIRA, Flávia (org.).Quando os professores investigam a pedagogia. Em busca de uma educação mais democrática. Portugal: Edições Pedago, outubro 2014.

ZEICHNER, K. A formação reflexiva de professores: ideias e práticas. Lisboa: Educa, 1993. 
ZEICHNER, K. M. Tendências da pesquisa sobre formação de professores nos Estados Unidos. Tradução de Lólio Lourenço de Oliveira e revisão de Elsa Garrido.Revista de Educação Brasileira, n. 9, p. 76-87, set./dez, 1998.

Recebido em março/2017

Aceito em maio/2017 